\title{
Electrical Properties of Rapidly Annealed Ir and Ir/Au Schottky Contacts on n-Type InGaN
}

\author{
V. Rajagopal Reddy, B. Prasanna Lakshmi, and R. Padma \\ Department of Physics, Sri Venkateswara University, Tirupati 517 502, India \\ Correspondence should be addressed to V. Rajagopal Reddy, reddy_vrg@rediffmail.com
}

Received 23 August 2011; Accepted 24 October 2011

Academic Editor: Stefano Gialanella

Copyright ( $) 2012$ V. Rajagopal Reddy et al. This is an open access article distributed under the Creative Commons Attribution License, which permits unrestricted use, distribution, and reproduction in any medium, provided the original work is properly cited.

\begin{abstract}
The effect of annealing temperature on electrical characteristics of iridium (Ir) and iridium/gold (Ir/Au) Schottky contacts to ntype InGaN have been investigated by means of current-voltage $(I-V)$ and capacitance-voltage $(C-V)$ techniques. It is observed that the barrier height of Ir/n-InGaN and $\mathrm{Au} / \mathrm{Ir} / \mathrm{n}$-InGaN Schottky diodes increases after annealing at $300^{\circ} \mathrm{C}$ for $1 \mathrm{~min}$ in $\mathrm{N}_{2}$ ambient compared to the as-deposited. However, the barrier heights are found to be decreased somewhat after annealing at $500^{\circ} \mathrm{C}$ for the both Ir and Ir/Au Schottky contacts. From the above observations, it is clear that the optimum annealing temperature for both $\mathrm{Ir}$ and Ir/Au Schottky contacts is $300^{\circ} \mathrm{C}$. Moreover, the barrier height $\left(\phi_{b}\right)$, ideality factor $(n)$ and series resistance $\left(R_{S}\right)$ are determined using Cheung's and Norde methods. Besides, the energy distribution of interface state densities are determined from the forward bias $I-V$ characteristics by taking into account the bias dependence of the effective barrier height. Based on the above results, it is clear that both Ir and Ir/Au Schottky contacts exhibit a kind of thermal stability during annealing.
\end{abstract}

\section{Introduction}

III-V nitride semiconductors, particularly gallium nitride $(\mathrm{GaN})$ and related alloys, have received much attention because of the (or their) wide range of practical applications. Among the ternary compounds of group III nitride materials, InGaN has drawn a great deal of attention. GaN and InGaN have been considered as the most important and crucial materials used for the fabrication of light emitters which were active in entire visible and part of the near UV spectral regions. The development of high-quality Schottky contacts to InGaN is difficult because in obtaining highquality InGaN layers with high composition of In, their low carrier mobility (compared to GaN), and a large amount of surface defects in InGaN layers [1]. Hence, the fabrication of Schottky contacts to InGaN with a high barrier height and good thermal stability is still a challenge.

Many research groups have extensively investigated the electrical properties of $\mathrm{n}-\mathrm{GaN}$ Schottky diodes using various metal schemes such as $\mathrm{W}, \mathrm{WSi}_{\mathrm{x}}$ [2], $\mathrm{Ru}, \mathrm{Ru} / \mathrm{Au}$ [3], Rh, $\mathrm{Rh} / \mathrm{Au}$ [4], Ni/Au [5], and Re [6]. Kim et al. [2] investigated the thermal stability of $\mathrm{W}$ and $\mathrm{WSi}_{\mathrm{x}}$ Schottky contacts on n-type GaN and reported that the $\mathrm{WSi}_{\mathrm{x}}$ contacts showed improved thermal stability compared to pure $\mathrm{W}$ contacts. They also reported that the $\mathrm{WSi}_{\mathrm{x}}$ contact was stable up to temperatures $>600^{\circ} \mathrm{C}$ with the Schottky barrier height $(\mathrm{SBH})$ of $\sim 0.5 \mathrm{eV}$. Rajagopal Reddy et al. [3] studied the influence of thermal annealing temperature on the electrical properties of $\mathrm{Ru}$ and $\mathrm{Ru} / \mathrm{Au}$ Schottky contacts to n-type $\mathrm{GaN}$. They found that the Ru Schottky contacts exhibit a kind of thermal stability during annealing compared to the $\mathrm{Ru} / \mathrm{Au}$ contacts. Rajagopal Reddy et al. [4] investigated the effect of annealing temperature on electrical properties of $\mathrm{Rh}$ and $\mathrm{Rh} / \mathrm{Au}$ Schottky contacts to n-type GaN. They reported that there was a significant improvement in the electrical characteristics of $\mathrm{Rh} / \mathrm{Au}$ Schottky contacts upon annealing compared to the Rh Schottky contacts. Miura et al. [5] investigated the thermal annealing effects on Ni/Aubased Schottky contacts on $\mathrm{n}-\mathrm{GaN}$ and AlGaN/GaN after inserting high work function metals such as $\mathrm{Pt}$, Ir, Pd, or Mo. Venugopalan and Mohney [6] showed that the Re Schottky contact was thermally stable on $\mathrm{n}-\mathrm{GaN}$ and reported a barrier height of $0.82 \mathrm{eV}$ and $1.06 \mathrm{eV}$ after annealing at $500^{\circ} \mathrm{C}$ by $I-V$ and $C-V$ methods. Jang et al. [7] investigated 


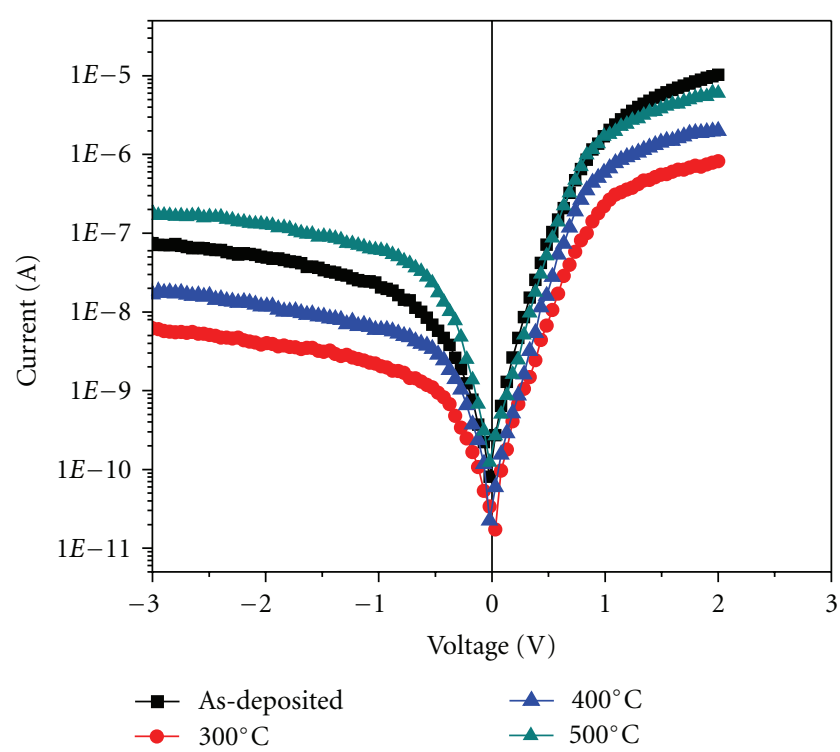

(a) Ir/n-InGaN Schottky diode.

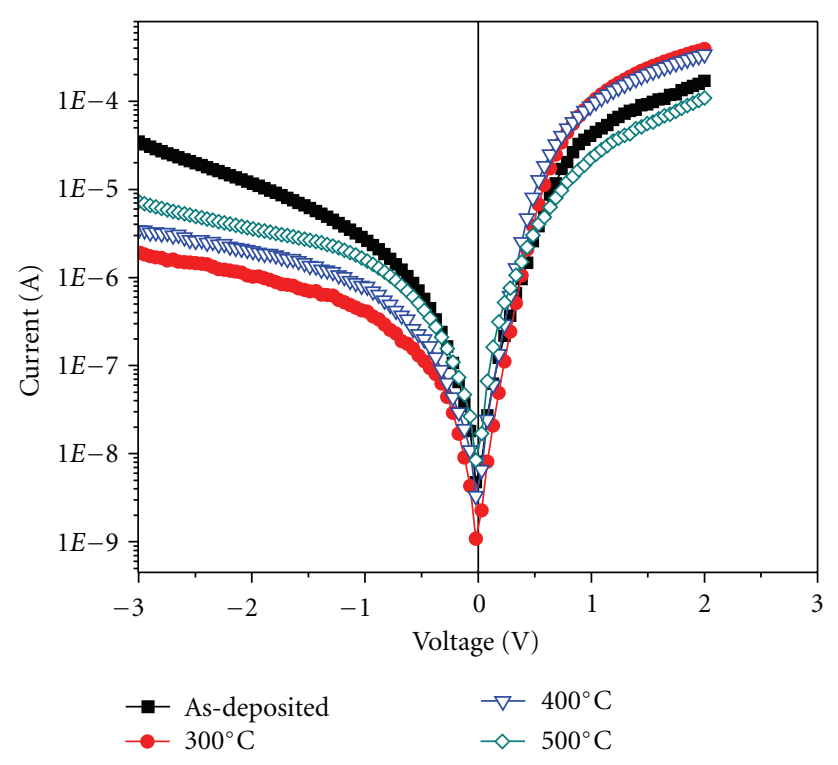

(b) $\mathrm{Au} / \mathrm{Ir} / \mathrm{n}-\mathrm{InGaN}$ Schottky diode.

FIgure 1: (a) The typical current-voltage characteristics for the Ir Schottky contacts on n-type InGaN. (b) The typical current-voltage characteristics for the Ir/Au Schottky contacts on n-type InGaN.

the Schottky barrier characteristics of Pt contacts on nInGaN by the $I-V$ and $C-V$ methods. They found that there was a large difference in SBHs obtained by the TE and TFE modes using the $I-V$ data. Xue et al. [8] fabricated large-area $\mathrm{Au} / \mathrm{Pt} / \mathrm{In}_{0.2} \mathrm{G}_{0.8} \mathrm{~N}$ Schottky contacts for photovoltaic devices and investigated the current transport mechanisms of the Schottky diodes with different background carrier concentrations.

There are, however, only limited works on metal-InGaN $\left(N_{d}=6 \times 10^{17} \mathrm{~cm}^{-3}\right)$ Schottky barriers. Hence, the main aim of the present work is to fabricate and characterize the Irbased Schottky contacts on InGaN. To the best of our knowledge, Ir metal scheme has not been explored as Schottky contacts on InGaN. In this work, Ir is selected because it has a high work function of $5.46 \mathrm{eV}$. From a device point of view, it is important to know what happens to metal contacts when they are annealed. Therefore, our main focus in the present work is to investigate the electrical characteristics of Ir and Ir/Au Schottky contacts on $\mathrm{n}-\mathrm{InGaN}$ by means of currentvoltage $(I-V)$ and capacitance-voltage $(C-V)$ measurements as a function of annealing temperature.

\section{Experimental Details}

$2 \mu$ m-thick unintentionally doped GaN layer on a $40 \mathrm{~nm}$ thick nucleation layer/(0001) sapphire substrate was grown by metal organic chemical vapor deposition (MOCVD). This was followed by the growth of $\sim 0.25 \mu$ m-thick n-InGaN: Si $\left(N_{d}=6 \times 10^{17} \mathrm{~cm}^{-3}\right)$ with $10 \%$ of indium (In) composition. Prior to the metal deposition, the n-type InGaN layer was first ultrasonically degreased with warm trichloroethylene followed by acetone, methanol, and ethanol for $5 \mathrm{~min}$ in each step and then rinsed with deionized (DI) water. This degreased layer was then dipped into boiling aquarezia $\left[\mathrm{HNO}_{3}: \mathrm{HCl}=1: 3\right]$ for $10 \mathrm{~min}$ to remove the native oxide. For ohmic contacts, bilayer of $\mathrm{Ti}(25 \mathrm{~nm}) / \mathrm{Al}(100 \mathrm{~nm})$ was deposited on InGaN and then annealed at $650^{\circ} \mathrm{C}$ for $1 \mathrm{~min}$ in flowing $\mathrm{N}_{2}$ atmosphere using rapid thermal annealing (RTA) system. Ir $(50 \mathrm{~nm})$ and $\mathrm{Ir} / \mathrm{Au}(20 \mathrm{~nm} / 30 \mathrm{~nm})$ Schottky contacts were fabricated on $\mathrm{n}-\mathrm{InGaN}$ with a circular diameter of $0.7 \mathrm{~mm}$ using electron beam evaporation system with a vacuum pressure of $5 \times 10^{-6} \mathrm{mbar}$. In order to investigate the thermal annealing effect on Schottky diodes, the Ir and $\mathrm{Ir} / \mathrm{Au}$ contacts were annealed at $300^{\circ} \mathrm{C}, 400^{\circ} \mathrm{C}$, and $500^{\circ} \mathrm{C}$ for $1 \mathrm{~min}$ in $\mathrm{N}_{2}$ ambient. The electrical characteristics of Schottky contacts were determined by means of currentvoltage $(I-V)$ and capacitance-voltage $(C-V)$ characteristics using Keithley source measure unit (model no. 2400) and deep level transient spectrometer (DLS-83 D), respectively.

\section{Results and Discussion}

3.1. Current-Voltage (I-V) Characteristics. Figures 1(a) and 1(b) show the semilogarithmic plots of forward and reverse $I$ $V$ characteristics of Ir and Ir/Au Schottky contacts measured as a function of annealing temperature. It is noted that the properties of Ir and Ir/Au Schottky diodes are uniform over different temperatures. It is observed that the leakage current of as-deposited Ir Schottky diode is $2.38 \times 10^{-8} \mathrm{~A}$ at $-1 \mathrm{~V}$. For the contact annealed at $300^{\circ} \mathrm{C}$, the leakage current decreases to $2.21 \times 10^{-9} \mathrm{~A}$, whereas for the contacts annealed at $400^{\circ} \mathrm{C}$ and $500^{\circ} \mathrm{C}$, the leakage current values are $6.0 \times 10^{-9} \mathrm{~A}$ and $6.49 \times 10^{-8} \mathrm{~A}$ at $-1 \mathrm{~V}$, respectively. In the case of as-deposited Ir/Au Schottky diode, the leakage current at $-1 \mathrm{~V}$ is $2.78 \times 10^{-6} \mathrm{~A}$. For the contacts annealed at $300^{\circ} \mathrm{C}$, $400^{\circ} \mathrm{C}$, and $500^{\circ} \mathrm{C}$, the obtained leakage current values are 
TABLE 1: The various parameters obtained from the $I-V$ and $C-V$ characteristics of $I r$ and $\mathrm{Ir} / \mathrm{Au}$ Schottky contacts on $\mathrm{n}$-InGaN as a function of annealing temperature.

\begin{tabular}{|c|c|c|c|c|c|c|c|c|}
\hline \multirow{3}{*}{ Sample } & \multirow{2}{*}{\multicolumn{3}{|c|}{$\begin{array}{l}\text { Schottky barrier height } \\
\quad(\mathrm{SBH}) \phi_{b}(\mathrm{eV})\end{array}$}} & \multirow{3}{*}{$\begin{array}{c}\text { From } I-V \\
n\end{array}$} & \multicolumn{4}{|c|}{ Cheung's functions } \\
\hline & & & & & \multicolumn{2}{|c|}{$d V / d \ln (I)$ versus $I$} & \multicolumn{2}{|c|}{$H(I)$ versus $I$} \\
\hline & $I-V$ & $C-V$ & Norde & & $R_{s}(\Omega)$ & $n$ & $\phi_{b}(\mathrm{eV})$ & $R_{s}(\Omega$ \\
\hline \multicolumn{9}{|l|}{ Ir } \\
\hline As-dep & 0.79 & 1.17 & 0.81 & 1.60 & 188 & 2.15 & 0.80 & 226 \\
\hline $300^{\circ} \mathrm{C}$ & 0.85 & 1.21 & 0.88 & 1.10 & 62 & 1.38 & 0.86 & 74 \\
\hline $400^{\circ} \mathrm{C}$ & 0.84 & 1.11 & 0.86 & 1.25 & 83 & 1.61 & 0.85 & 102 \\
\hline $500^{\circ} \mathrm{C}$ & 0.80 & 1.07 & 0.82 & 1.50 & 122 & 1.93 & 0.81 & 133 \\
\hline \multicolumn{9}{|l|}{$\mathrm{Ir} / \mathrm{Au}$} \\
\hline As-dep & 0.70 & 1.00 & 0.73 & 1.51 & 171 & 1.93 & 0.71 & 179 \\
\hline $300^{\circ} \mathrm{C}$ & 0.74 & 1.03 & 0.76 & 1.23 & 90 & 1.46 & 0.75 & 109 \\
\hline $400^{\circ} \mathrm{C}$ & 0.71 & 0.96 & 0.74 & 1.43 & 109 & 1.89 & 0.72 & 128 \\
\hline $500^{\circ} \mathrm{C}$ & 0.67 & 0.93 & 0.71 & 1.77 & 231 & 2.04 & 0.68 & 260 \\
\hline
\end{tabular}

$4.22 \times 10^{-7} \mathrm{~A}, 7.87 \times 10^{-7} \mathrm{~A}$, and $1.66 \times 10^{-6} \mathrm{~A}$ at $-1 \mathrm{~V}$, respectively. The smallest leakage current values are obtained for both Ir and Ir/Au Schottky contacts after annealing at $300^{\circ} \mathrm{C}$, accompanied by the corresponding increase in the barrier height. This indicates that the electrical characteristics of both the Ir and Ir/Au contacts are improved upon annealing at $300^{\circ} \mathrm{C}$ compared to the as-deposited contacts. It also is noted that the reverse leakage current decreased for Ir/n-InGaN Schottky diode compared to the Au/Ir/n-InGaN Schottky diode upon annealing temperature.

The barrier height and the ideality factor of a metal-semiconductor contact are determined using thermionic emission theory and are given by [9]

$$
I=I_{S} \exp \left[\left(\frac{q(V-I R)}{n K T}\right)-1\right]
$$

with

$$
I_{S}=A A^{* *} T^{2} \exp \left(\frac{-q \phi_{b}}{k T}\right) .
$$

Here, $I_{S}$ is the saturation current, $q$ is the electron charge, $V$ is the applied voltage, $R$ is the series resistance, $T$ is the absolute temperature, $n$ is the ideality factor, $k$ is the Boltzmann's constant, $A$ is the contact area, and $A^{* *}$ is the effective Richardson constant. The theoretical value of $A^{* *}$ was $23 \mathrm{~A} \mathrm{~cm}^{-2} \mathrm{~K}^{-2}$ based on the effective mass $\left(m^{*}=0.19 m_{0}\right)$

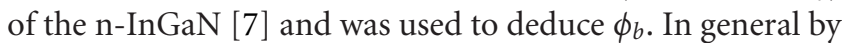
using a linear curve fit to the forward characteristics of $\ln (I)$ against $V$ data, barrier height $\left(\phi_{b}\right)$ and ideality factor $(n)$ can be determined from the $y$-intercept and the slope of the fitted curve, respectively. Calculations yield that the Schottky barrier height (SBH) of as-deposited Ir/n-InGaN Schottky diode is $0.79 \mathrm{eV}$. For the contacts annealed at $300^{\circ} \mathrm{C}, 400^{\circ} \mathrm{C}$, and $500^{\circ} \mathrm{C}$, the calculated barrier heights are $0.85 \mathrm{eV}, 0.84 \mathrm{eV}$, and $0.80 \mathrm{eV}$. The Schottky barrier height estimated in the case of $\mathrm{Ir} / \mathrm{Au}$ contact is $0.70 \mathrm{eV}$ (as-deposited), $0.74 \mathrm{eV}$ after annealing $\left(\right.$ at $\left.300^{\circ} \mathrm{C}\right), 0.71 \mathrm{eV}\left(400^{\circ} \mathrm{C}\right)$, and $0.67 \mathrm{eV}\left(500^{\circ} \mathrm{C}\right)$.

The ideality factor is determined from $I-V$ plot, specifically at small forward currents, where the effect of series resistance is considered to be small. In case of Ir and Ir/Au Schottky diodes, the typical values of ideality factor are found to be 1.60 and 1.51 (as-deposited), respectively. However, it is observed that the ideality factors are improved to 1.10 for Ir and 1.23 for Ir/Au Schottky contacts upon annealing at $300^{\circ} \mathrm{C}$. The ideality factor calculated from the forward bias $I-V$ plot is found to be greater than unity. This may be due to a potential drop in the interface layer and the presence of excess current and the recombination current through the interfacial state between the semiconductor/insulator layers [10]. Also, when the bias is applied, part of the voltage is dropped across the interface layers. Thus, the barrier height becomes dependent on the bias voltage, leading to an ideality factor greater than one. Moreover, the larger values of ideality factors are attributed to secondary mechanisms that include interface dipoles due to interface doping or specific interface structure as well as fabricate-induced defects at the interface $[11,12]$. The high value of ideality factor can also be attributed to the presence of a wide distribution of low$\mathrm{SBH}$ patches caused by laterally inhomogeneous according to Tung [13]. Another possibility may be the image-force effect, recombination generation, and tunneling mechanisms that could be lead to the ideality factor value greater than unity [14]. The barrier heights and the ideality factors of Ir and Ir/Au Schottky diodes as a function of annealing temperature are given in Table 1.

Generally, at low voltages, the linear forward bias current-voltage $(I-V)$ characteristics in the semilogarithmic scale deviate considerably from linearity, which is due to the effect of parameters such as $R_{S}$ and $N_{\mathrm{SS}}$ when the applied voltage is sufficiently large. The series resistance values are evaluated using the method developed by S. cheung and $\mathrm{N}$. cheung [15]. Cheung's functions given as

$$
\begin{aligned}
\frac{d V}{d(\ln I)} & =I R_{S}+n\left(\frac{k T}{q}\right), \\
H(I) & =V-n\left(\frac{k T}{q}\right) \ln \left(\frac{I}{A A^{* *} \mathrm{~T}^{2}}\right), \\
H(I) & =I R_{S}+n \phi_{b}
\end{aligned}
$$




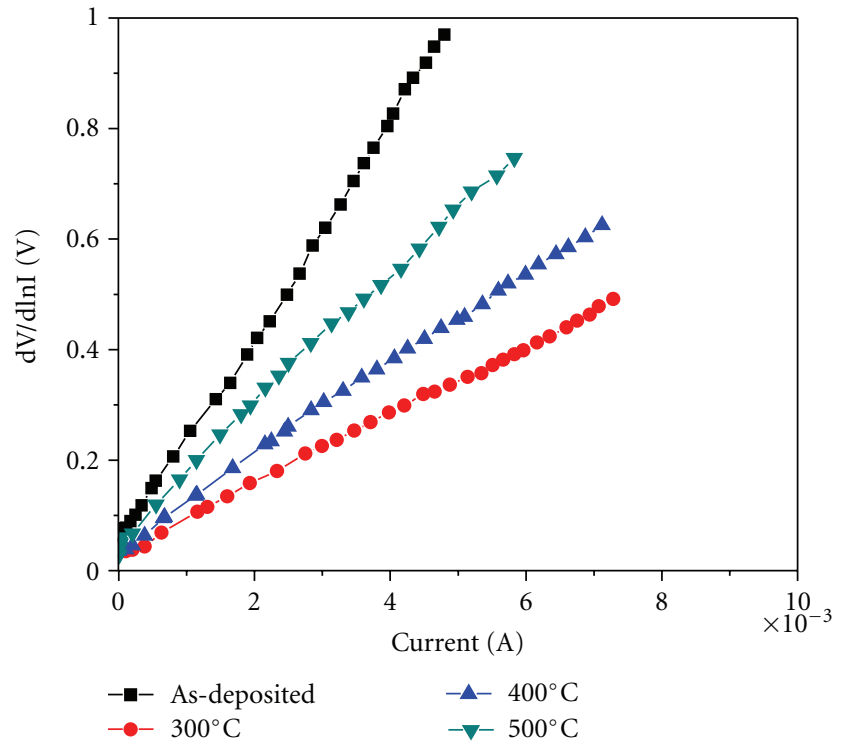

(a) $\mathrm{Ir} / \mathrm{n}-\mathrm{InGaN}$ Schottky diode.

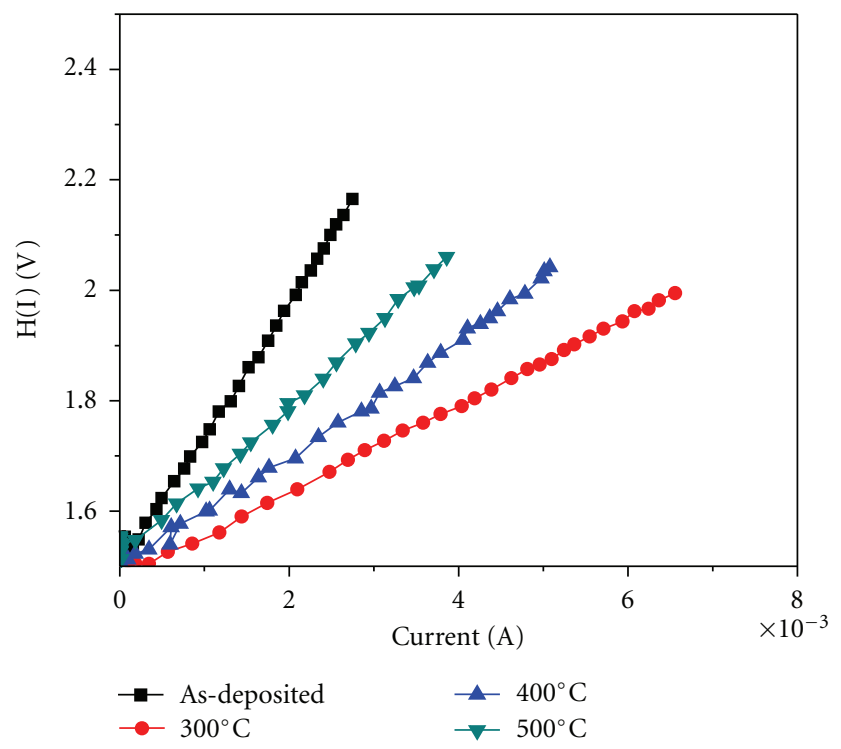

(b) Ir/n-InGaN Schottky diode.

Figure 2: (a) Plot of $d V / d \ln I$ versus $I$ for the Ir/n-InGaN Schottky contacts. (b) Plot of $H(I)$ versus $I$ for the Ir/n-InGaN Schottky contacts.

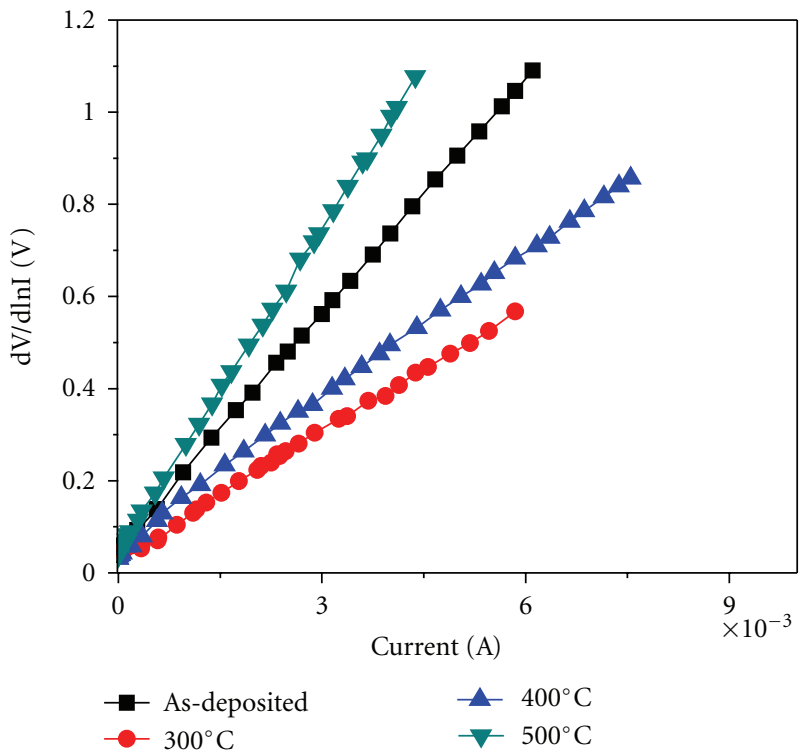

(a) $\mathrm{Au} / \mathrm{Ir} / \mathrm{n}-\mathrm{InGaN}$ Schottky diode.

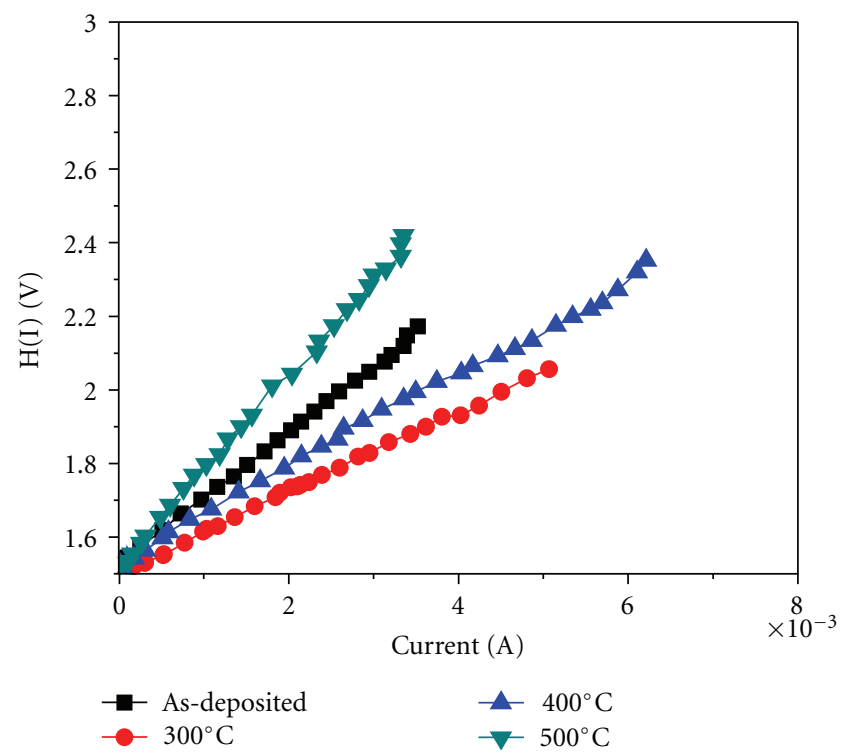

(b) $\mathrm{Au} / \mathrm{Ir} / \mathrm{n}-\mathrm{InGaN}$ Schottky diode.

Figure 3: (a) Plot of $d V / d \ln I$ versus $I$ for the Ir/Au/n-InGaN Schottky contacts. (b) Plot of $H(I)$ versus $I$ for the Ir/Au/n-InGaN Schottky contacts.

should give a straight line for the data of downward curvature region in the forward bias $I-V$ characteristics. The term $I R_{S}$ is the current drop across the series resistance of Schottky diodes. Figures 2(a) and 3(a) show the experimental $d V / d \ln I$ versus $I$ plot for the Ir and Ir/Au Schottky diodes, respectively. The values of $R_{S}$ and $n k T / q$ are calculated from the slope and $y$-axis intercepts of the $d V / d \ln I$ versus I plot, respectively. From Figures 2(b) and 3(b), it is evident that the plot of $H(I)$ versus $I$ gives a straight line with the $y$ axis intercept equal to $n \phi_{b}$, and the slope parameter can be used to check the consistency of Cheung's method. From (3), the values of ideality factor and series resistance for $\mathrm{Ir} / \mathrm{InGaN}$ and $\mathrm{Au} / \mathrm{Ir} / \mathrm{InGaN}$ Schottky diodes are calculated. The values of barrier height and series resistance for $\mathrm{Ir} / \mathrm{InGaN}$ and $\mathrm{Au} / \mathrm{Ir} / \mathrm{InGaN}$ Schottky diodes are calculated from (5) which is given in Table 1. Thus, it can be clearly seen that there is relatively a difference between the values of ideality factor calculated from the downward curvature regions of forward bias $I-V$ plots and from the linear regions of the same characteristics. This can be attributed to the existence of 


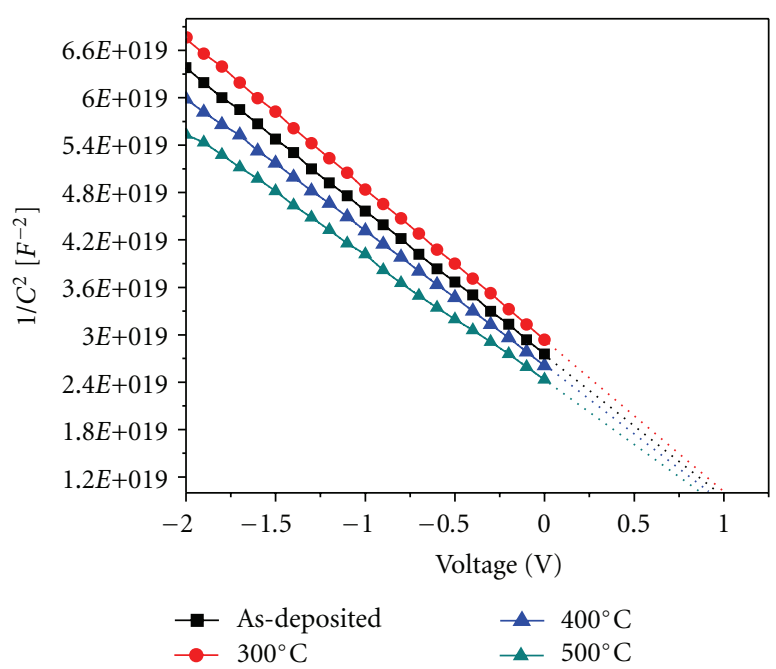

(a) Ir/n-InGaN Schottky diode.

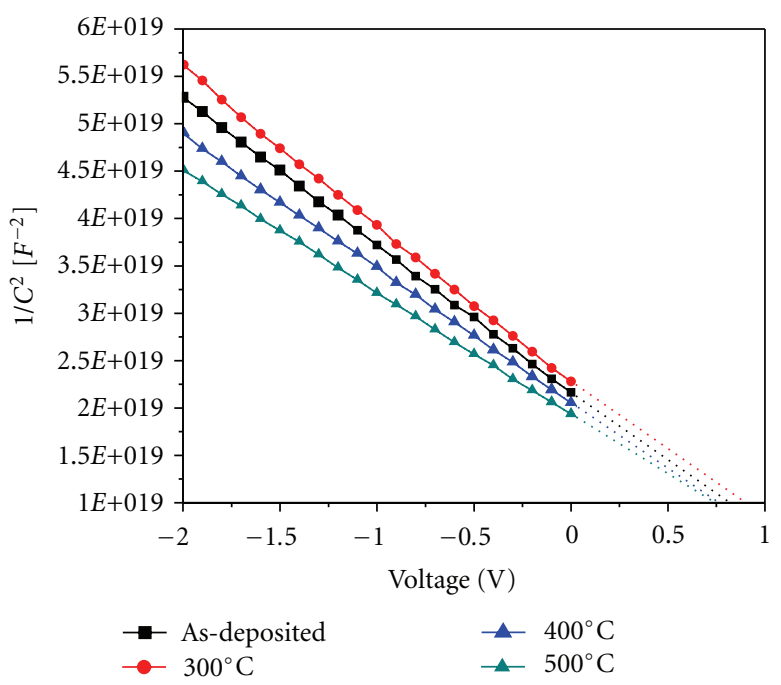

(b) $\mathrm{Au} / \mathrm{Ir} / \mathrm{n}-\mathrm{InGaN}$ Schottky diode.

Figure 4: (a) Plot of $1 / C^{2}$ versus $V$ for the Ir Schottky contacts annealed at different temperatures. (b) Plot of $1 / C^{2}$ versus $V$ for the Ir/Au Schottky contacts annealed at different temperatures.

effects such as series resistance and the bias dependence of Schottky barrier height according to the voltage drop across the interfacial layer and change of the interface states with the bias in the low-voltage region of the current-voltage plot.

The accurate evaluation of the barrier height from the standard ln $(I)-V$ plot can be effected by the high series resistance. To include this effect, Norde method is also used to compare the SBH of Ir and Ir/Au Schottky contacts. The Norde function $F(V)$, being plotted against $V \cdot F(V)$, is given by $[16,17]$

$$
F(V)=\frac{V}{2}-\frac{k T}{q} \ln \left[\frac{I(V)}{A A^{* *} T^{2}}\right] .
$$

The Schottky barrier height $\phi_{b}$ is given by

$$
\phi_{b}=F\left(V_{\min }\right)+\frac{V_{\min }}{2}-\frac{k T}{q},
$$

where $F\left(V_{\min }\right)$ is the minimum value of $F(V)$, and $V_{\min }$ is the corresponding voltage. Measurements showed that the SBHs are $0.81 \mathrm{eV}$ for as-deposited, $0.88 \mathrm{eV}$ for $300^{\circ} \mathrm{C}, 0.86 \mathrm{eV}$ for $400^{\circ} \mathrm{C}$, and $0.82 \mathrm{eV}$ for $500^{\circ} \mathrm{C}$ for Ir Schottky contacts. In the case of Ir/Au Schottky contacts, the calculated barrier heights are $0.73 \mathrm{eV}$ for as-deposited, $0.76 \mathrm{eV}$ for $300^{\circ} \mathrm{C}, 0.74 \mathrm{eV}$ for $400^{\circ} \mathrm{C}$, and $0.71 \mathrm{eV}$ for $500^{\circ} \mathrm{C}$, respectively. It is observed that these values are in good agreement with those calculated by $I-V$ method.

3.2. Capacitance-Voltage (C-V) Characteristics. Capacitancevoltage $(C-V)$ characteristics of Ir and Ir/Au Schottky contacts are measured at a frequency of $1 \mathrm{MHz}$ with an ac modulation of $100 \mathrm{mV}$ in the dark. Figures 4(a) and 4(b) show plots of $1 / C^{2}$ as a function of bias voltage for as-deposited and annealed contacts of Ir and Ir/Au Schottky contacts, respectively. The $C-V$ relationship for Schottky diode is given by [9]

$$
\frac{1}{C^{2}}=\frac{2\left[V_{b i}-(k T / q)-V\right]}{A^{2} q N_{d} \varepsilon_{S}},
$$

where $V_{b i}$ is the flat band voltage, $N_{d}$ is the donor concentration, $A$ is the area of the Schottky contact, and $\varepsilon_{s}$ is the permittivity of the semiconductor $\left(\varepsilon_{s}=8.4 \varepsilon_{o}\right)$. The $\mathrm{x}$ intercept of the plot of $\left(1 / C^{2}\right)$ versus $V, V_{o}$ is related to the built in potential $V_{b i}$ by equation $V_{b i}=V_{o}+k T / q$, where $T$ is the absolute temperature. The barrier height $\left(\phi_{C V}\right)$ is given by the equation $\phi_{C V}=V_{b i}+V_{n}$ where $V_{n}=(k T / q) \ln \left(N_{C} / N_{d}\right)$. The density of states in the conduction band edge is given by $N_{c}=2\left(2 \pi m^{*} k T / h^{2}\right)^{3 / 2}, m^{*}=$ $0.19 m_{o}$, and its value was $7 \times 10^{17} \mathrm{~cm}^{-3}$ for InGaN at room temperature. Measurements showed that the barrier heights of Ir Schottky contacts are $1.17 \mathrm{eV}$ for as-deposited, $1.21 \mathrm{eV}$ for $300^{\circ} \mathrm{C}, 1.11 \mathrm{eV}$ for $400^{\circ} \mathrm{C}$, and $1.07 \mathrm{eV}$ for $500^{\circ} \mathrm{C}$ annealed contacts. For Ir/Au Schottky contacts, the estimated barrier heights are $1.00 \mathrm{eV}$ (as-deposited), $1.03 \mathrm{eV}$ after annealing the contacts $\left(\right.$ at $\left.300^{\circ} \mathrm{C}\right), 0.96 \mathrm{eV}\left(400^{\circ} \mathrm{C}\right)$, and $0.93 \mathrm{eV}\left(500^{\circ} \mathrm{C}\right)$ by $C-V$ method.

Figure 5(a) shows a plot of barrier height of $\mathrm{Ir} / \mathrm{n}-\mathrm{InGaN}$ as a function of annealing temperature. It can be seen clearly from Figure 5(a) that the barrier height of Ir/n-InGaN Schottky diode increases upon annealing at $300^{\circ} \mathrm{C}$ for $1 \mathrm{~min}$ in the $\mathrm{N}_{2}$ ambient compared to the as-deposited contact. However, there is a slight decrease in the Schottky barrier height for the contacts annealed at $400^{\circ} \mathrm{C}$ and $500^{\circ} \mathrm{C}$. The interface states and chemical reactions between metals and semiconductors at the interface may be the reason for the variation in the barrier heights [18]. From Figure 5(a), it is also noted that the ideality factor is improved and reaches near unity value (1.10) after annealing at $300^{\circ} \mathrm{C}$. However, the values of 


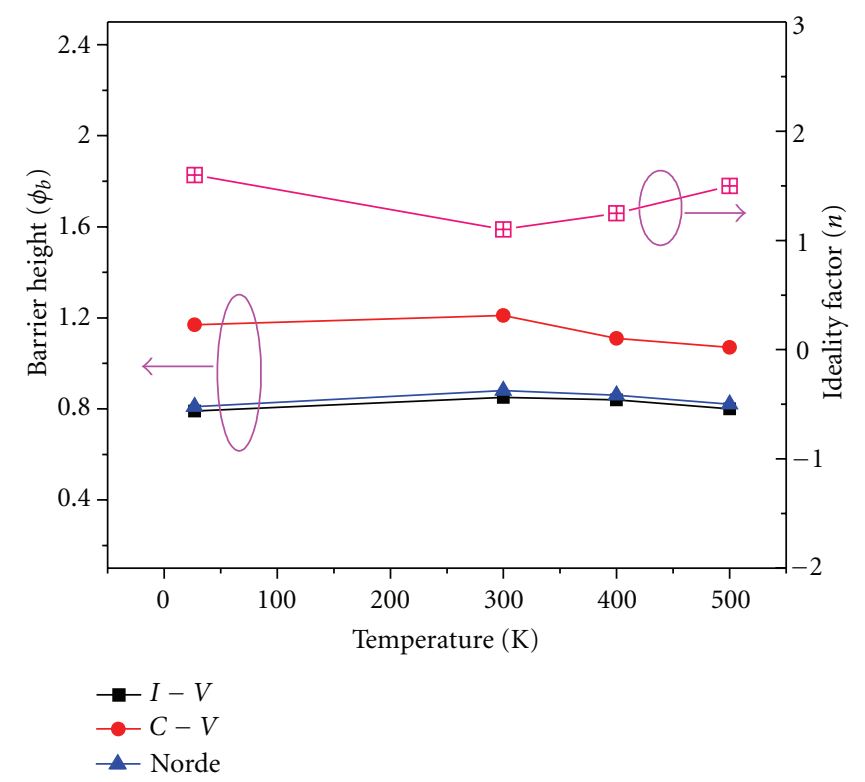

(a) Ir/n-InGaN Schottky diode.

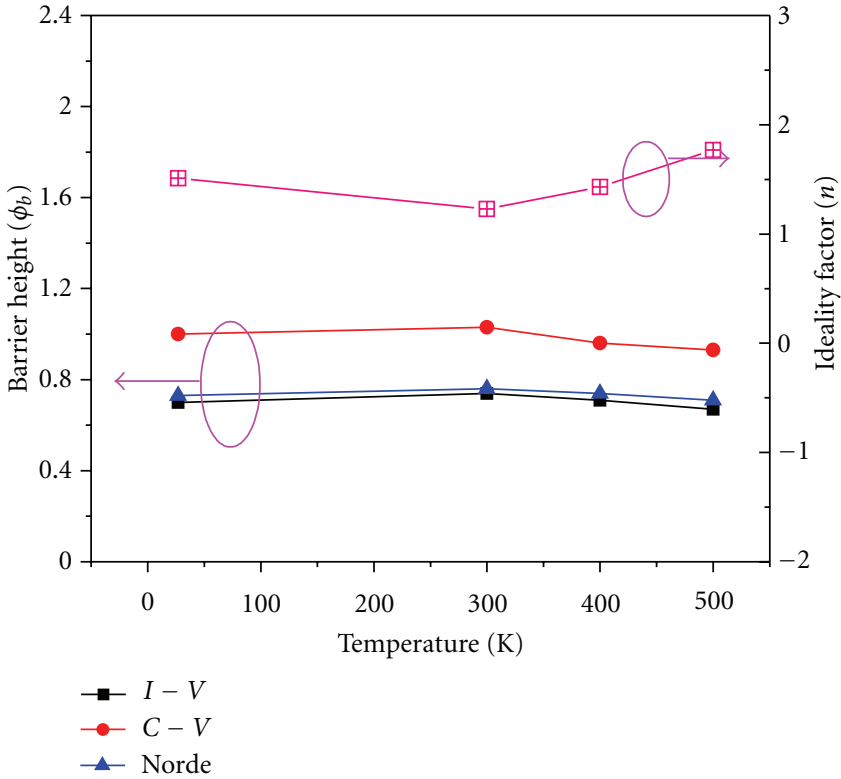

(b) $\mathrm{Au} / \mathrm{Ir} / \mathrm{n}-\mathrm{InGaN}$ Schottky diode.

FIGURE 5: (a) The barrier height and ideality factors of the Ir Schottky contact as a function of annealing. (b) The barrier height and ideality factors of the Ir/Au Schottky contact as a function of annealing.

ideality factor slightly increase upon annealing at $400^{\circ} \mathrm{C}$ and $500^{\circ} \mathrm{C}$ compared to the contact annealed at $300^{\circ} \mathrm{C}$.

The plot of barrier heights and ideality factors of Ir/Au Schottky contacts as a function of annealing temperature is shown in Figure 5(b). It is noted that the barrier height calculated for the as-deposited $\mathrm{Ir} / \mathrm{Au}$ contacts is less than annealed contacts $\left(300^{\circ} \mathrm{C}\right.$ and $\left.400^{\circ} \mathrm{C}\right)$. When the contact is annealed at $300^{\circ} \mathrm{C}$, it is found that the Schottky barrier height increases for Ir/Au contact. Rajagopal Reddy et al. [3] had observed similar behavior in $\mathrm{Au} / \mathrm{Ru} / \mathrm{n}-\mathrm{GaN}$ Schottky diode. Also, Miura et al. [5] had observed similar behavior in $\mathrm{Ni} / \mathrm{Pt} / \mathrm{Au}, \mathrm{Ni} / \mathrm{Au}$, and $\mathrm{Ni} / \mathrm{Mo} / \mathrm{Au}$ Schottky contacts on $\mathrm{n}-\mathrm{GaN}$. Upon annealing temperature, the increase in the barrier height may be due to the reduction in the nonstoichiometric defects in the metallurgical interface $[19$, 20]. Also, it is observed that the increase in the barrier height is accompanied by the corresponding decrease in the reverse leakage current. Duboz et al. [21] had reported that the metal/n-GaN interface remains unaffected even after annealing. They also found that the nature of the metal does not play a major role in the improvement of barrier height on annealing temperature. Many researchers had observed the pinning of Fermi level at metal/n-GaN interface because of the interface defects. Further, a modification in the defect density on annealing could change the pinning, which leads to the change of barrier height. Significant improvement in the electrical characteristics in the case of $\mathrm{Ir} / \mathrm{n}-\mathrm{InGaN}$ Schottky diode is observed upon annealing temperature compared to the $\mathrm{Au} / \mathrm{Ir} / \mathrm{n}-\mathrm{InGaN}$ Schottky diode. It is also observed that the electrical characteristics of Ir Schottky contacts are fairly more thermally stable than that of $\operatorname{Ir} / \mathrm{Au}$ Schottky contacts. Also, Figure 5(b) shows that the ideality factor value decreases upon annealing at $300^{\circ} \mathrm{C}$. With a further increase in the annealing temperatures up to $500^{\circ} \mathrm{C}$, the ideality factor is slightly increased.

It can also be seen from Figures 5(a) and 5(b) that the barrier heights obtained from $I-V$ measurements are lower than those obtained from $C-V$ measurements. This difference in the values of $\phi_{I-V}$ and $\phi_{C-V}$ may be due to the presence of native oxide layer at the metal/InGaN interface [22]. Lowering the barrier height by an image force due to current flow across the barrier can also have some effect [9]. However, with high-temperature annealing, the metal perhaps comes into intimate contact with the semiconductor. Furthermore, the differences in the barrier height calculated from $I-V$ and $C-V$ methods may also cause the Schottky barrier height inhomogeneities that prevail at the metal semiconductor interface [23]. Another possibility is that the surface damage at the metal-semiconductor interface affects $I-V$ measurements because defects may act as recombination centers for trap-assisted tunneling currents. $C$ - $V$ measurements are normally less prone to interface states. Hence, the calculated barrier heights are considered more reliable, though the depletion width can be altered by interface defects if they are deeper into the space charge region [24]. It may also be the transport mechanism in these diodes which is not purely due to thermionic emission. To these diodes, $\phi_{b}$ obtained from $I-$ $V$ method is voltage or electric field sensitive unlike the $\phi_{b}$ obtained from $C-V$.

3.3. Interface State Density ( $\left.N_{S S}\right)$ from $I-V$ and $C-V$ Measurements. It is noted from Figures 6(a) and 6(b) that the interface state density $N_{S S}$ has an exponential increase with the bias from the midgap towards the top of the conduction 


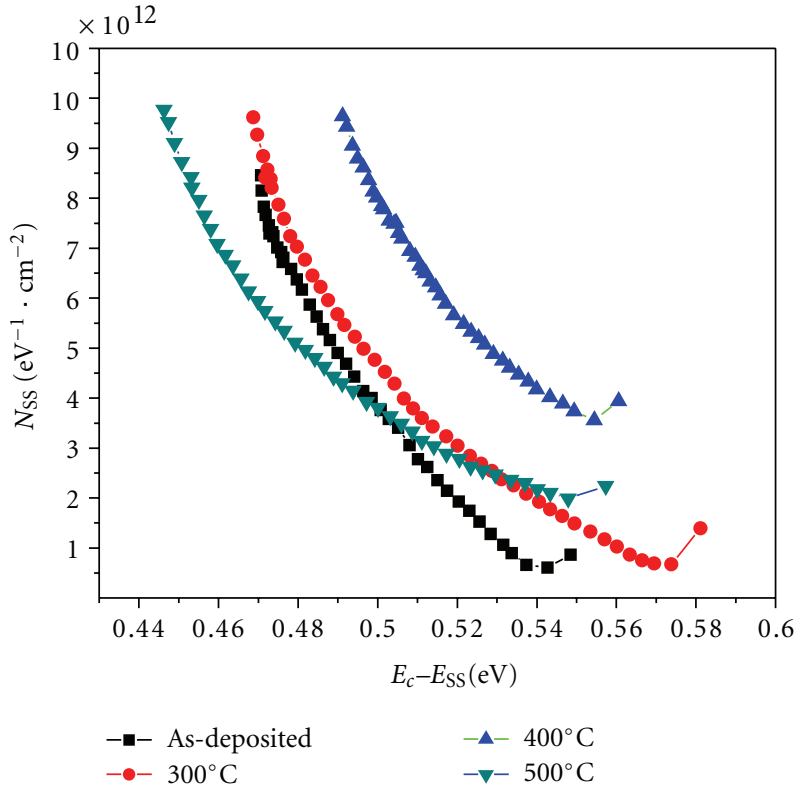

(a) Ir/n-InGaN Schottky diode.

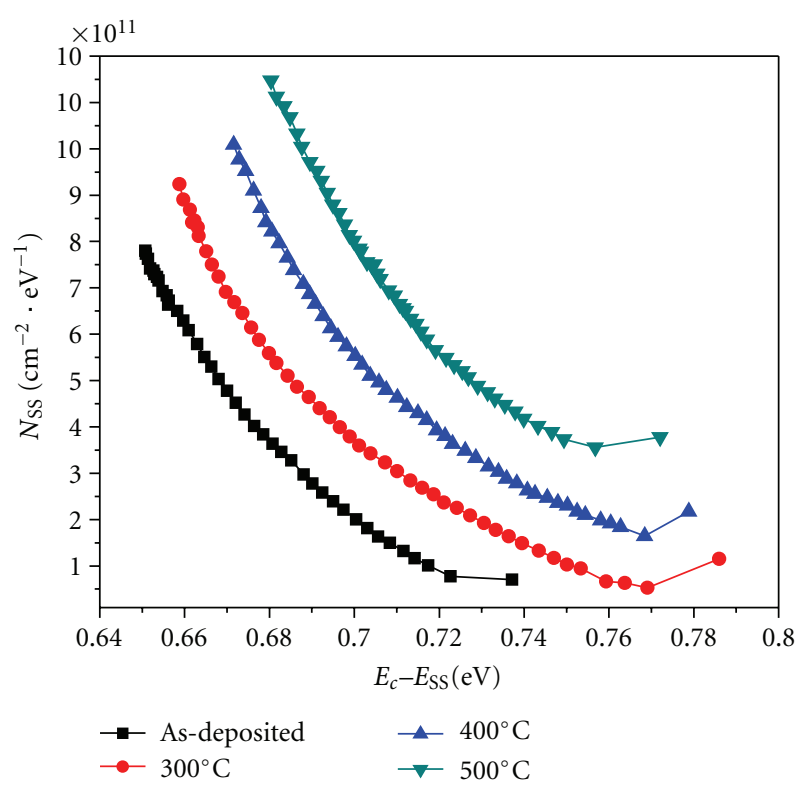

(b) $\mathrm{Au} / \mathrm{Ir} / \mathrm{n}-\mathrm{InGaN}$ Schottky diode.

Figure 6: (a) Interface state density distribution profiles as a function of $E_{C C}-E_{S S}$ for Ir Schottky contacts. (b) Interface state density distribution profiles as a function of $E_{C C}-E_{S S}$ for Ir/Au Schottky contacts.

band. According to Card and Rhoderick, for a real Schottky diode having interface states in equilibrium with the semiconductor, the ideality factor $n$ becomes greater than unity and is given by $[9,25]$

$$
n(V)=1+\frac{\delta}{\varepsilon_{i}}\left[\frac{\varepsilon_{S}}{W_{d}}+q \cdot N_{\mathrm{ss}}(V)\right],
$$

where $N_{S S}$ is the density of interface states, $W_{d}$ is the width of the semiconductor, and $\varepsilon_{S}$ and $\varepsilon_{i}$ are the permittivity of the semiconductor and the interfacial layer, respectively. The voltage-dependent ideality factor $n(V)$ can be expressed as $n(V)=(q V) /\left(k T \ln \left(I / I_{s}\right)\right)$ [26]. The expression for the interface state density can be given as

$$
N_{\mathrm{SS}}=\frac{1}{q}\left[\frac{\varepsilon_{i}}{\delta}(n(V)-1)-\frac{\varepsilon_{S}}{W_{d}}\right] .
$$

In the n-type semiconductor, the energy of the interface states $E_{\mathrm{SS}}$ with respect to the bottom of the conduction band at the surface of the semiconductor is given by $[25,27,28]$

$$
E_{C}-E_{S S}=q\left(\phi_{e}-V\right),
$$

where $\phi_{e}$ is the effective barrier height. The voltage dependence of the effective barrier height $\phi_{e}$ is contained in the ideality factor $n$ through the relation

$$
\frac{d \phi_{e}}{d V}=\beta=1-\frac{1}{n(V)},
$$

where $\beta$ is the voltage coefficient of $\phi_{e}$. The effective barrier height $\phi_{e}$ is given by [29]

$$
\phi_{e}=\phi_{b}+\beta(V) .
$$

From Figures 6(a) and 6(b), it can be seen that the $N_{S S}$ value decreases with the increase in the $E_{C}-E_{S S}$ value. The increase in $N_{\text {SS }}$ values forms from midgap towards the bottom of the conduction band which is probably due to the increase in the series resistance $\left(R_{S}\right)$. The change in the charge of the interface states and thus the interface state energy distribution due to the potential drop across the interfacial layer varies with the bias. It alters the diffusion potential and therefore the depletion capacitance $[9,30-33]$.

\section{Conclusions}

We have investigated the electrical properties of Ir and $\mathrm{Ir} / \mathrm{Au}$ Schottky contacts on n-type InGaN $\left(N_{d}=6 \times\right.$ $10^{17} \mathrm{~cm}^{-3}$ ) by $I-V$ and $C-V$ measurements as a function of annealing temperature. Measurements showed that the barrier height of as-deposited Ir Schottky contact is $0.79 \mathrm{eV}$ ( $I$ $V)$ and $1.17 \mathrm{eV}(C-V)$. Upon annealing at $300^{\circ} \mathrm{C}$ for $1 \mathrm{~min}$ in nitrogen ambient, the Schottky barrier height increases to $0.85 \mathrm{eV}(I-V)$ and $1.12 \mathrm{eV}(C-V)$. After annealing at $400^{\circ} \mathrm{C}$ and $500^{\circ} \mathrm{C}$, the Schottky barrier heights decrease to $0.84 \mathrm{eV}(I-V), 1.11 \mathrm{eV}(C-V)$ and $0.80 \mathrm{eV}(I-V), 1.07$ $(C-V)$. In the case of as-deposited Ir/Au Schottky contacts, the estimated barrier height is $0.70 \mathrm{eV}(I-V)$ and $1.00 \mathrm{eV}$ $(C-V)$. However, the Schottky barrier height increases upon annealing temperature at $300^{\circ} \mathrm{C}$, and the corresponding value is $0.74 \mathrm{eV}(I-V)$ and $1.03 \mathrm{eV}(C-V)$. Further, with an increase in annealing temperature up to $500^{\circ} \mathrm{C}$, the barrier height decreases to $0.67 \mathrm{eV}(I-V)$ and $0.93 \mathrm{eV}(C-V)$, respectively. Based on the above results, the optimum barrier heights are obtained after annealing at $300^{\circ} \mathrm{C}$ for both Ir and Ir/Au Schottky contacts. Therefore, the optimum annealing 
temperature for both Ir and Ir/Au Schottky contacts is $300^{\circ} \mathrm{C}$. The values of diode parameters such as ideality factor $(n)$, series resistance $\left(R_{S}\right)$, and barrier height $\left(\phi_{b}\right)$ are also calculated by Cheung's and Norde's methods. The interface state density has an exponential raise with bias from the midgap towards the top of the conduction band. From the above observations, it is clear that the electrical properties of Ir and Ir/Au Schottky contacts are improved with an increase in annealing temperature compared to the as-deposited one. Moreover, both Ir and Ir/Au Schottky contacts showed relatively thermal stability during annealing temperature.

\section{Acknowledgment}

The authors thank the University Grant Commission (UGC), New Delhi, for providing the financial assistance (Grant no. 39-530/2010 (SR)).

\section{References}

[1] S. X. Li, K. M. Yu, J. Wu et al., "Fermi-level stabilization energy in group III nitrides," Physical Review B, vol. 71, no. 16, pp. 14, 2005.

[2] J. Kim, F. Ren, A. G. Baca, and S. J. Pearton, "Thermal stability of WSix and W Schottky contacts on n-GaN," Applied Physics Letters, vol. 82, no. 19, pp. 3263-3265, 2003.

[3] V. Rajagopal Reddy, C. K. Ramesh, and K. S. R. Koteswara Rao, "Effect of annealing temperature on electrical characteristics of ruthenium-based Schottky contacts on n-type GaN," Journal of Materials Science, vol. 17, no. 12, pp. 999-1004, 2006.

[4] V. Rajagopal Reddy and N. Ramesha Reddy, "Influence of thermal annealing temperature on electrical properties of Rh and $\mathrm{Rh} / \mathrm{Au}$ Schottky contacts to n-type GaN," Journal of Optoelectronics and Advanced Materials, vol. 9, no. 12, pp. 3871-3876, 2007.

[5] N. Miura, T. Nanjo, M. Suita et al., "Thermal annealing effects on Ni/Au based Schottky contacts on n-GaN and AlGaN/GaN with insertion of high work function metal," Solid-State Electronics, vol. 48, no. 5, pp. 689-695, 2004.

[6] H. S. Venugopalan and S. E. Mohney, "Thermally stable rhenium Schottky contacts to n-GaN," Applied Physics Letters, vol. 73, no. 9, pp. 1242-1244, 1998.

[7] J. S. Jang, D. Kim, and T. Y. Seong, "Schottky barrier characteristics of Pt contacts to n-type InGaN," Journal of Applied Physics, vol. 99, no. 7, Article ID 073704, 2006.

[8] J. J. Xue, D. J. Chen, B. Liu et al., "Au/Pt/InGaN/GaN heterostructure schottky prototype solar cell," Chinese Physics Letters, vol. 26, no. 9, Article ID 098102, 2009.

[9] E. H. Rhoderick and T. H. Williams, Metal-Semiconductor Contacts, Oxford Science, Oxford, UK, 1988.

[10] D. T. Quan and H. Hbib, "High barrier height Au/n-type InP Schottky contacts with a $\mathrm{POxNyHz}$ interfacial layer," SolidState Electronics, vol. 36, no. 3, pp. 339-344, 1993.

[11] C. R. Crowell, "The Richardson constant for thermionic emission in Schottky barrier diodes," Solid State Electronics, vol. 8, no. 4, pp. 395-399, 1965.

[12] H. Çetin and E. Ayyildiz, "Electrical characteristics of Au, $\mathrm{Al}, \mathrm{Cu} / \mathrm{n}$-InP Schottky contacts formed on chemically cleaned and air-exposed n-InP surface," Physica B, vol. 394, no. 1, pp. 93-99, 2007.
[13] R. T. Tung, "Recent advances in Schottky barrier concepts," Materials Science and Engineering: $R$, vol. 35, no. 1-3, pp. 113, 2001.

[14] L. Messick, "A D.C. to $16 \mathrm{GHz}$ indium phosphide MISFET," Solid State Electronics, vol. 23, no. 6, pp. 551-555, 1980.

[15] S. K. Cheung and N. W. Cheung, "Extraction of Schottky diode parameters from forward current-voltage characteristics," Applied Physics Letters, vol. 49, no. 2, pp. 85-87, 1986.

[16] H. Norde, "A modified forward I-V plot for Schottky diodes with high series resistance," Journal of Applied Physics, vol. 50, no. 7, pp. 5052-5053, 1979.

[17] J. S. Jang, S. J. Park, and T. Y. Seong, "Formation of low resistance Pt ohmic contacts to p-type GaN using two-step surface treatment," Journal of Vacuum Science and Technology B, vol. 17, no. 6, pp. 2667-2670, 1999.

[18] S. Yuunping, X. M. Shen, J. Wang et al., "Thermal annealing behaviour of Ni/Au on n-GaN Schottky contacts," Journal of Physics D, vol. 35, no. 20, pp. 2648-2651, 2002.

[19] W. E. Spicer, I. Lindau, P. Skeath, C. Y. Su, and P. Chye, "Unified mechanism for schottky-barrier formation and III-V oxide interface states," Physical Review Letters, vol. 44, no. 6, pp. 420-423, 1980.

[20] R. H. Williams, V. Montgomery, and R. R. Varma, "Chemical effects in Schottky barrier formation," Journal of Physics C, vol. 11, no. 17, pp. L735-L738, 1978.

[21] J. Y. Duboz, F. Binet, N. Laurent et al., "Influence of surface defects on the characteristics of GaN Schottky diodes," Material Research Society Symposium Proceedings, vol. 449, pp. 1085-1090, 2009.

[22] V. Rajagopal Reddy, M. Ravinandan, P. Koteswara Rao, and C. J. Choi, "Effects of thermal annealing on the electrical and structural properties of Pt/Mo Schottky contacts on n-type GaN," Journal of Materials Science, vol. 20, no. 10, pp. 10181025, 2009.

[23] J. H. Werner and H. H. Güttler, "Barrier inhomogeneities at Schottky contacts," Journal of Applied Physics, vol. 69, no. 3, pp. 1522-1533, 1991.

[24] C. Fontaine, T. Okumura, and K. N. Tu, "Interfacial reaction and Schottky barrier between Pt and GaAs," Journal of Applied Physics, vol. 54, no. 3, pp. 1404-1412, 1983.

[25] H. C. Card and E. H. Rhoderick, "Studies of tunnel MOS diodes I. Interface effects in silicon Schottky diodes," Journal of Physics D, vol. 4, no. 10, pp. 1589-1601, 1971.

[26] O. Güllü and A. Türüt, "Electrical analysis of organic interlayer based metal/interlayer/ semiconductor diode structures," Journal of Applied Physics, vol. 106, no. 10, Article ID 103717, 2009.

[27] A. Singh, K. C. Reinhardt, and W. A. Anderson, "Temperature dependence of the electrical characteristics of $\mathrm{Yb} / \mathrm{p}$-InP tunnel metal-insulator-semiconductor junctions," Journal of Applied Physics, vol. 68, no. 7, pp. 3475-3483, 1990.

[28] M. K. Hudait and S. B. Krupanidhi, "Interface states density distribution in $\mathrm{Au} / \mathrm{n}-\mathrm{GaAs}$ Schottky diodes on $\mathrm{n}-\mathrm{Ge}$ and $\mathrm{n}$ GaAs substrates," Materials Science and Engineering B, vol. 87, no. 2, pp. 141-147, 2001.

[29] A. Turut, M. Saglam, H. Efeoglu, N. Yalcin, M. Yildirim, and B. Abay, "Interpreting the nonideal reverse bias $\mathrm{C}-\mathrm{V}$ characteristics and importance of the dependence of Schottky barrier height on applied voltage," Physica B, vol. 205, no. 1, pp. 41-50, 1995.

[30] S. M. Sze, Physics of Semiconductor Structures, John Wiley \& Sons, New York, NY, USA, 2nd edition, 1981. 
[31] S. Karatas, S. Altindal, and M. Cakar, "Current transport in $\mathrm{Zn/p-Si}\left(\begin{array}{lll}1 & 0 & 0\end{array}\right)$ Schottky barrier diodes at high temperatures," Physica B, vol. 357, no. 3-4, pp. 386-397, 2005.

[32] S. Karatas and A. Turut, "The determination of electronic and interface state density distributions of Au/n-type GaAs Schottky barrier diodes," Physica B, vol. 381, no. 1-2, pp. 199-203, 2006.

[33] A. Turut and M. Saglam, "Determination of the density of Simetal interface states and excess capacitance caused by them," Physica B, vol. 179, no. 4, pp. 285-294, 1992. 

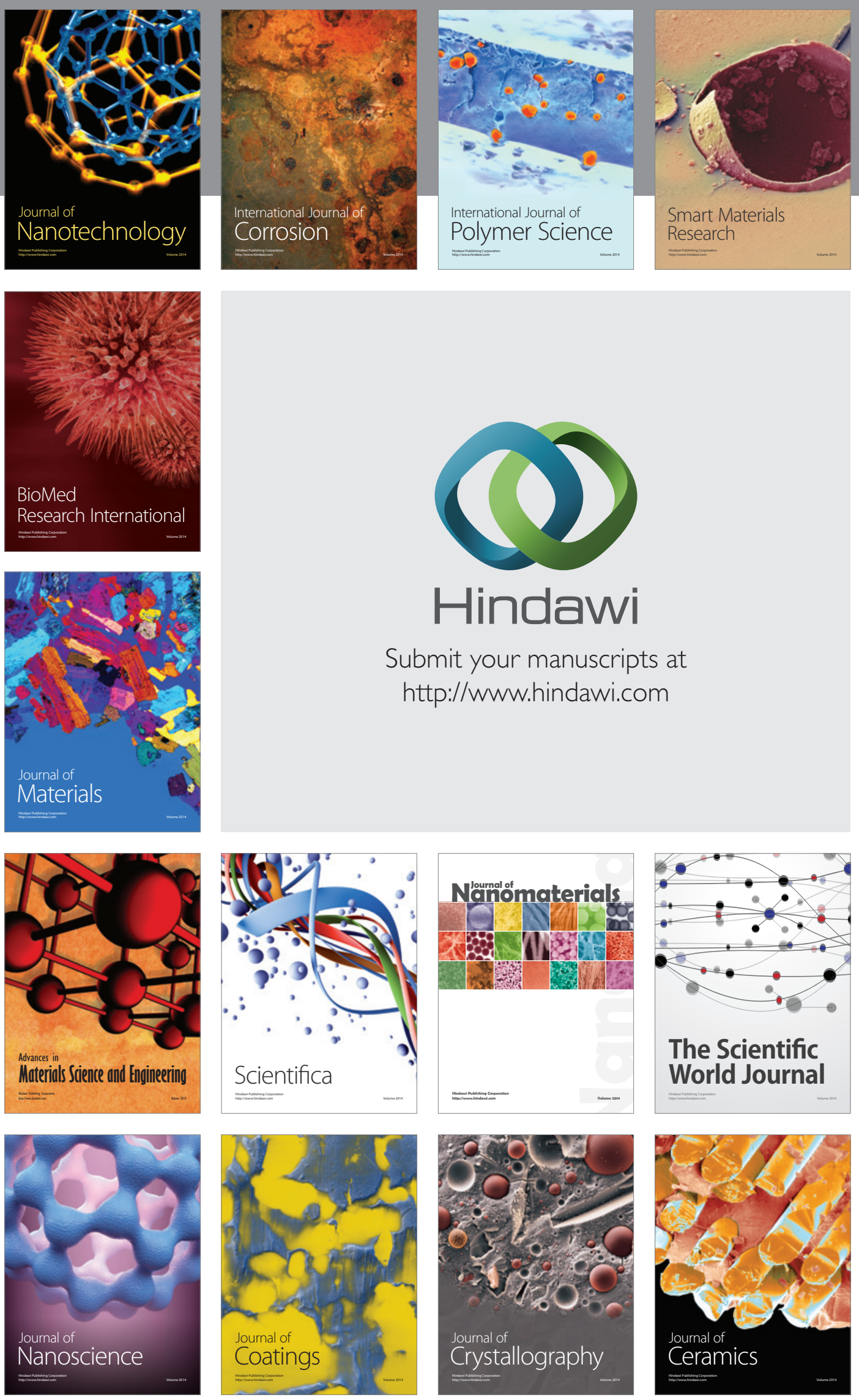

The Scientific World Journal

Submit your manuscripts at

http://www.hindawi.com

\section{World Journal}

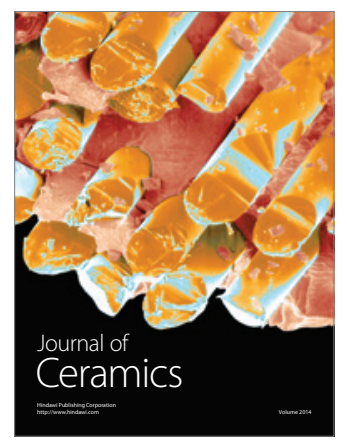

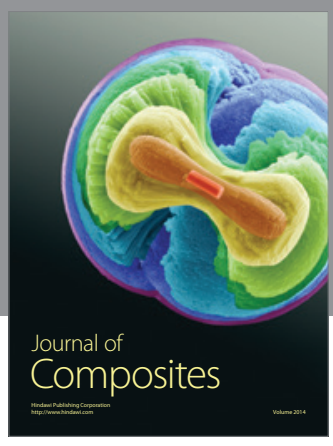
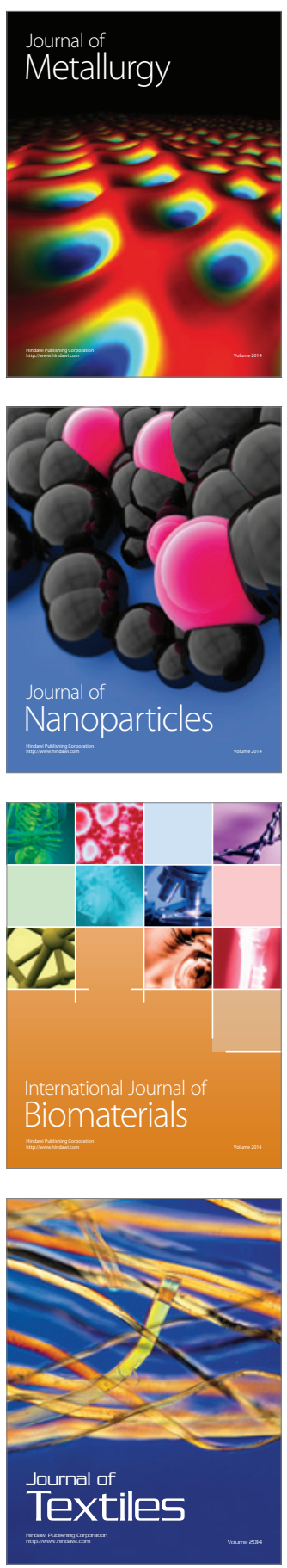